\title{
In situ XRPD of the synthesis of corundum from boehmite during ball milling
}

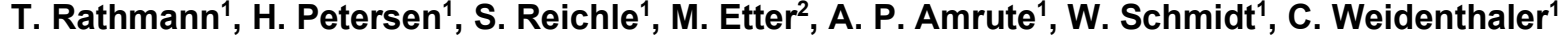 \\ ${ }^{1}$ Max-Planck-Institut für Kohlenforschung, Heterogeneous Catalysis, Kaiser-Wilhelm-Platz 1, 45470 Mülheim, Germany, \\ ${ }^{2}$ Deutsches Elektronen-Synchrotron (DESY), Notkestraße 85, 22607 Hamburg, Germany \\ weidenthaler@mpi-muelheim.mpg.de
}

The possibility to induce transformations in solid materials by grinding is known since ancient times [1]. While in those times only simple tools like mortar and pestle were available, laboratories nowadays use automatized milling instruments. Well-known examples for these tools are ball mills, for which shaker and planetary ball mills are the most widely used types [1,2]. Since 2013, in situ X-ray powder diffraction (in situ XRPD) is applied to study processes taking place in shaker mills [3]. By using high-energy synchrotron radiation, it is possible to monitor transitions of crystalline compounds and the appearance of intermediate crystalline phases during grinding in real-time [3, 4]. Special adaptations of the grinding setup are necessary to fulfill the criteria for the successful performance of such in situ studies [3, 4]. Two aspects are especially important. On the one hand, the material composition and the wall thicknesses of the applied vessels determine the remaining intensity of the diffracted X-rays [5]. On the other hand, the used mill must provide a free pathway for the X-rays, which is not the case for conventional shaker mills [4]. The established way to ensure the fulfillment of both conditions is the use of vessels made from polymethyl methacrylate (PMMA) together with a modified shaker mill $[4,5]$. This combination allowed for the successful in situ XRPD monitoring of the syntheses of soft materials by ball milling, like metal organic frameworks or organic co-crystals [3-5]. Recently, the utilization of an alternative vessel design was published for the successful in situ XRPD study of the mechanochemical synthesis of zinc sulfide from its elements [6]. In this case, the vessel was made of a material mix of stainless steel and PMMA. Despite these successful applications, the in situ monitoring of hard materials, which have a high demand towards the mechanical properties of the grinding tools, remain especially challenging. In this work, we present the first in situ XRPD data of the mechanochemically induced transformation of boehmite $(\gamma-\mathrm{AlOOH})$ to corundum ( $\left.\alpha-\mathrm{Al}_{2} \mathrm{O} 3\right)$. So far, the transformation could only be shown by ex situ XRD data [7]. As one of the hardest materials, corundum is especially suited to explore the limits of a grinding system. We will discuss the specific demands, which arise for in situ XRPD of hard materials during ball milling and their technical solutions.

[1] Balaz, P., Achimovicova, M., Balaz, M., Billik, P., Cherkezova-Zheleva, Z., Criado, J. M., Delogu, F., Dutkova, E., Gaffet, E., Gotor, F. J., Kumar, R., Mitov, I., Rojac, T., Senna, M., Streletskii, A. \& Wieczorek-Ciurowa, K. (2013). Chem. Soc. Rev. 42, $7571-7637$.

[2] Friscic, T., Mottillo, C. \& Titi, H. M. (2020). Angew. Chem., Int. Edit. 59, 1018-1029.

[3] Friscic, T., Halasz, I., Beldon, P. J., Belenguer, A. M., Adams, F., Kimber, S. A. J., Honkimaki, V. \& Dinnebier, R. E. (2013). Nat. Chem., 5, 66-73.

[4] Halasz, I., Kimber, S. A. J., Beldon, P. J., Belenguer, A. M., Adams, F., Honkimaki, V., Nightingale, R. C., Dinnebier, R. E. \& Friscic, T. (2013). Nat. Protoc., 8, 1718-1729.

[5] Halasz, I., Friscic, T., Kimber, S. A. J., Uzarevic, K., Puskaric, A., Mottillo, C., Julien, P., Strukil, V., Honkimaki, V. \& Dinnebier, R. E. (2014). Faraday Discuss., 170, 203-221.

[6] Petersen, H., Reichle, S., Leiting, S., Losch, P., Kersten, W., Rathmann, T., Tseng, J., Etter, M., Schmidt, W. \& Weidenthaler, C. (2021). Chem. Eur. J. 10.1002/chem.202101260

[7] Amrute, A. P., Lodziana, Z., Schreyer, H., Weidenthaler, C. \& Schüth, F. (2019). Science, 366, $485-489$.

\section{Keywords: X-ray powder diffraction; mechanochemistry; in situ}

We acknowledge DESY (Hamburg, Germany) a member of the Helmholtz Association HGF, for the provision of experimental facilities. Parts of this research were carried out at PETRA III, beamline P02.1.

Furthermore, we acknowledge the fine mechanics workshop of the Max-Planck-Institut für Kohlenforschung for the construction of the milling vessels and the modifications of the utilized shaker mill.

We thank Isabella Kappel, Priyanka Sharma and Jan Ternieden for their support in conducting experiments at the beamline. 